\title{
ОСНОВНЫЕ ПРИНЦИПЫ ПРОЕКТИРОВАНИЯ ИТ-ИНФРАСТРУКТУРЫ ЦИФРОВОГО ПРЕДПРИЯТИЯ
}

\section{BASIC PRINCIPLES OF DESIGNING THE IT INFRASTRUCTURE OF A DIGITAL ENTERPRISE}

\section{T. Andrusenko \\ V. Azarov}

Summary. In this article deals with questions connected with transformation of business architecture of the enterprise, with introduction of digital technologies at all stages of full life cycle of the producing goods or services. The main stages of designing corporate computer networks, the organizational structure of a digital enterprise are considered.

Keywords: Bigital transformation, business architecture, corporate information systems, management of the information and communications technologies, information security, data and knowledge management.

\author{
Андрусенко Татьяна Анатольевна \\ Аспирант, Российский университет транспорта \\ (МИИТ), г. Москва) \\ tati.and01@gmail.com \\ Азаров Владимир Николаевич \\ Профессор, Российский университет транспорта \\ (МИИТ), г. Москва \\ vazarov52@gmail.com
}

Аннотация. В статье рассматриваются вопросы, связанные с трансформацией бизнес - архитектуры предприятия, с внедрением цифровых технологий на всех этапах полного жизненного цикла производства продукции или услуги. Рассмотрены основные этапы проектирования корпоративных компьютерных сетей, организационная структура цифрового предприятия.

Ключевые слова: цифровая трансформация, бизнес-архитектура, корпоративные информационные системы, управление информационно-коммуникационными технологиями, информационная безопасность предприятия, управление данными и знаниями.

на соответствие определённым стандартам, существуют другие виды сертификации (например, на уровень зрелости), которым создаваемая ИСМ должна соответствовать.

В Индустрии 4.0 трансформируются все отраслевые предприятия, которые можно разделить на группы:

- первая - это добывающие или производящие природные ресурсы;

- вторая - это предприятия, выполняющие переработку природного сырья, добытого или произведенного предприятиями первой группы

- третья - это предприятия сферы общественных услуг.

Для качественного функционирования таких предприятий в условиях Индустрии 4.0 необходимо внедрение новых цифровых технологий, которые можно разделить на десять технологических информационных областей: горизонтальная и вертикальная системная интеграция, моделирование, интернет вещей, кибербезопасность, облачные технологии, анализ больших данных, аддитивное производство (3D-печать), роботы, дополненная реальность, смарт- управление [1].

При автоматизации процессов накоплен большой опыт применения различных информационных технологий и информационных систем, таких как: CAD/ CAM/ 


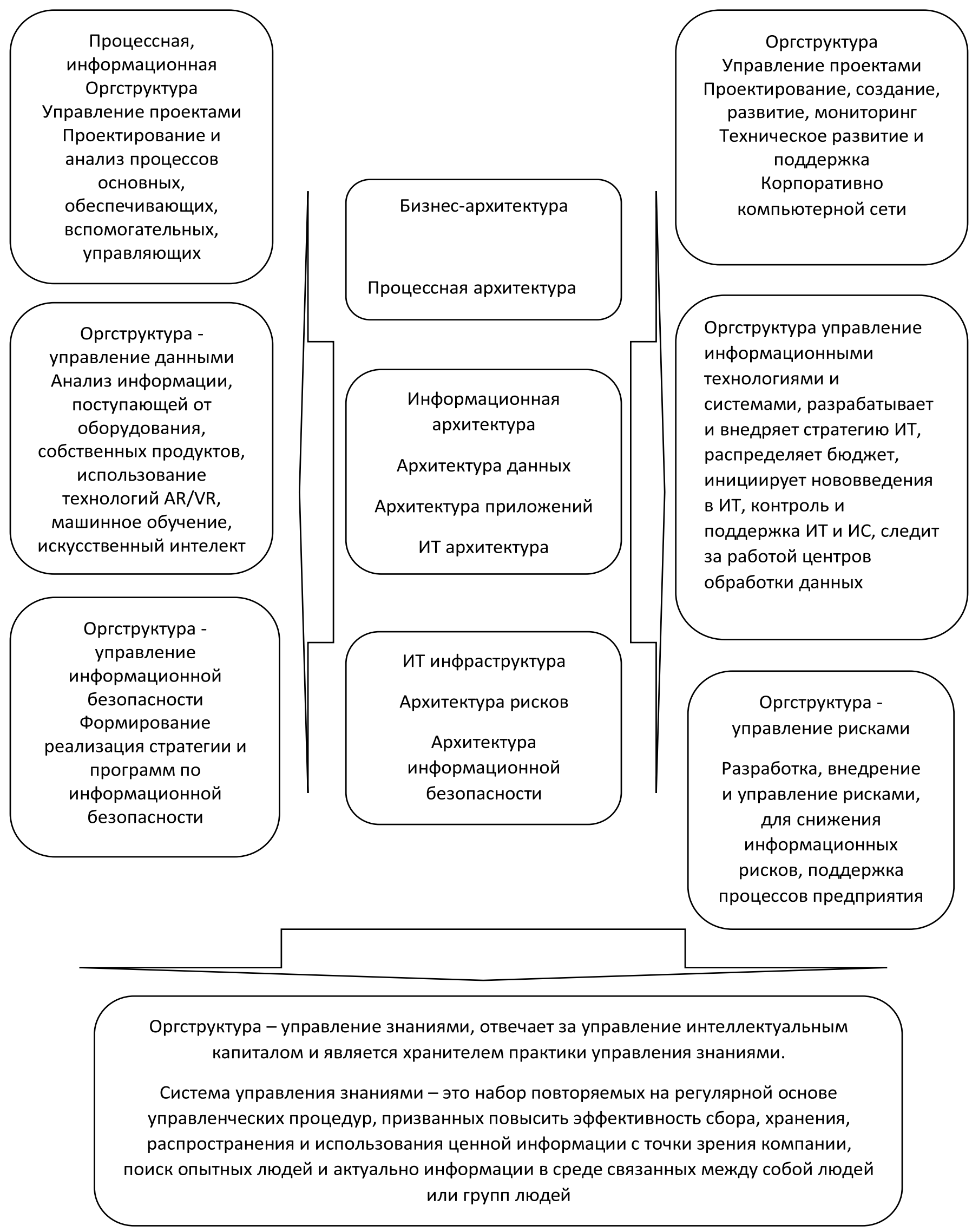

Рис. 1. Архитектурная модель оргструктуры предприятия. 


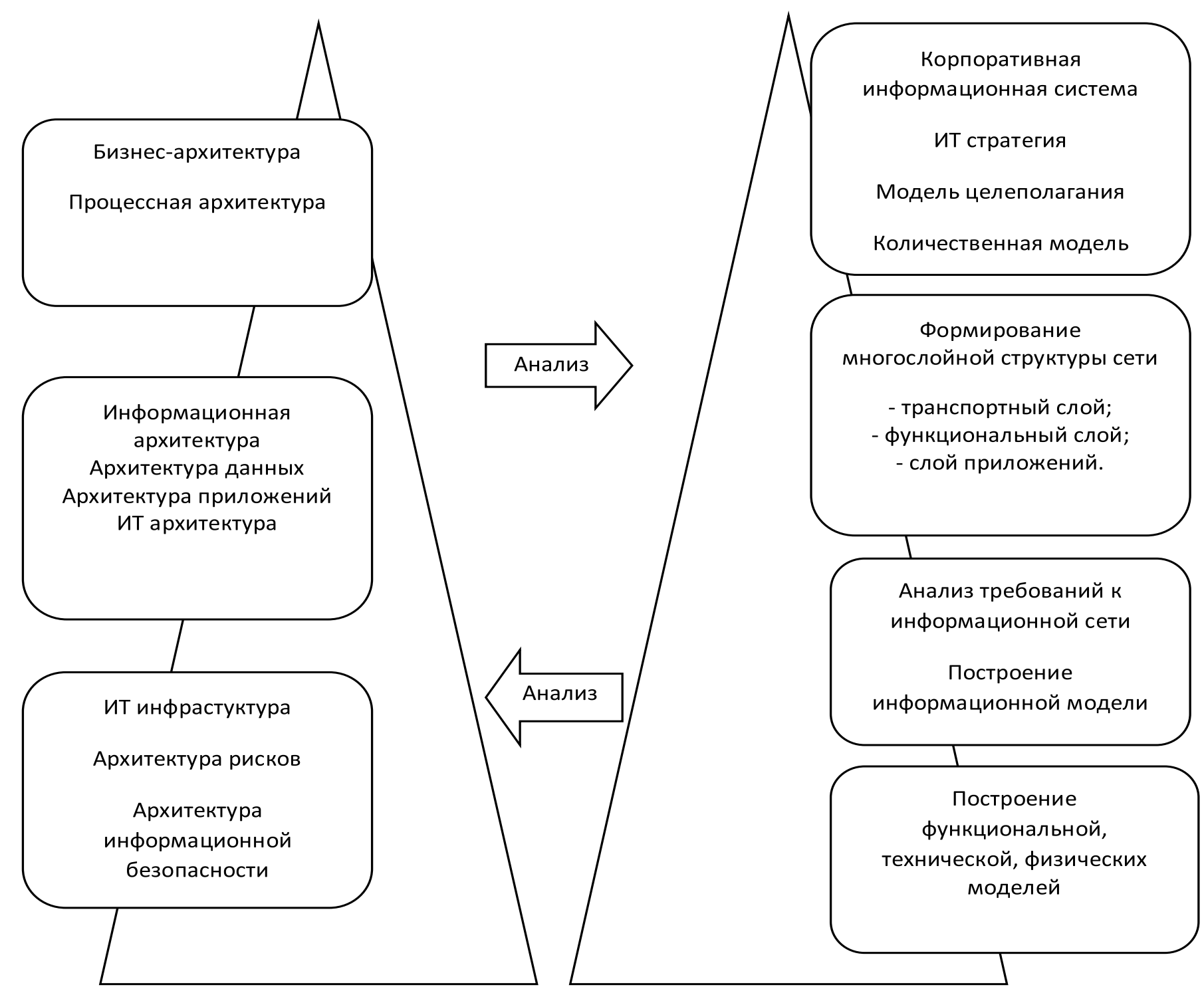

Рис. 2. Формирование архитектуры корпоративной информационной системы

CAE, системы ED, CRM и ERP, MRP, BPM, CASE, OLAP, Специальные системы СMK, B2G, B2B, В2С, автоматизированные линии и многое другое.

Интенсивное развитие информационных технологий (ИТ) и информационных систем (ИС) привело к необходимости разработки и создания новых стандартов, таких как ISO 20000, ISO 27000, ISO 31000 и многих других. Эффективное применение этих стандартов на практике требует разработки нового подхода к созданию интегрированных систем менеджмента качества (ИСМК) и её трансформация в интегрированные системы общего менеджмента (ИСМ) предприятия.

В таких условиях необходимо реализовывать основные направления деятельности компании в виде сово- купности всех систем и процессов. При этом появляется проблема, которая заключается в отсутствии этих систем и процессов, а также систем управления данными и систем управления знаниями. Это касается не только всех бизнес-процессов самой компании, но и создаваемых компанией продукции.

При проектировании оргструктуры предприятия, интегрированной системы менеджмента и его ИТ-инфраструктуры в условиях цифровой трансформации необходимо использовать архитектурный подход.

Выбор международных стандартов, используемых при проектировании интегрированной системы менеджмента, организационно-функциональной структуры управления определяется целями, задачами и отраслевой направ- 
ленностью организации, а в качестве исходной модели необходимо использовать представление модернизированною модель архитектуры предприятия [2].

Архитектура предприятия неразрывно связанна с используемыми информационными технологиями и информационными системами, которые обеспечивают получение, обработку, хранение и передачу информации на все уровни организации и информационный обмен с внешним миром. Архитектура корпоративных информационных систем (КИС) строится под бизнес-архитектуру, и обратно трансформируется бизнес-архитектура.

К проектированию ИСМ (Интегрированная Система Менеджмента) цифрового предприятия необходимо подходить с двух позиций:

1. Взаимодействующие бизнес-процессы и бизнес-правила, структура и потоки информации.

2. С позиции технических понятий, таких, как аппаратные и компьютерные средства, программное обеспечение, информационная безопасность.

Архитектура предприятия связывает информационные технологии, бизнес - потребности предприятия, процессы стратегического бизнес - планирования, прикладные информационные системы и процессы их сопровождения.

Архитектура предприятия состоит:

- из системы процессов организации - это основа системного внедрения процессного подхода, из моделей, политик, правил или стандартов, определяющих, какие данные собираются и как они хранятся, размещаются, интегрируются и используются в системах данных и в организациях;

- архитектуры приложений, представленную набор прикладных систем, необходимых предприятию для выполнения бизнес-процессов и разработки прикладных систем;

- архитектуру рисков, включающую риски и организационные структуры, ответственные за управление соответствующими рисками.

- архитектуру информационной безопасности, включающую процессы, роли людей, технологии и разные типы информации. В архитектуру ИБ, безусловно, входят и организационные структуры, ответственные за соответственные зоны безопасности [3].

Анализируя архитектуру предприятия, очевидно, возможно выделить основные бизнес-подразделения цифрового предприятия (рис. 1).

Информационная архитектура, архитектура данных и приложений и ИТ-архитектура образуют корпоратив- ную информационную систему организации, процесс формирования которой представлен на рис. 2.

Анализируя такой подход к рассмотрению архитектуры, мы можем предложить принципы формирования проектной команды разработчиков ИСМ и команды из состава руководителей и функциональных исполнителей предприятия [4].

Безусловно, команда разработчиков должна включать: специалиста в области управления качеством, бизнес-аналитика, финансового аналитика, архитектора решений, системного архитектора, ИТ-менеджера, менеджера информационных систем, менеджера систем информационной безопасности, менеджера рисков, менеджеров в области экологии и безопасности труда и др. Безусловно, из этого вытекает и кадровый состав службы качества предприятия и других функциональных подразделений. Кроме того, из этого следует, какой стандарт следует применять и на каком этапе создания ИСМ.

Одним из главных направлений цифровой трансформации производства является переход к управлению через данные и качеству данных, которые можно классифицировать как данные о предмете с различных сторон.

Возглавляет данное направление в организации CDO (Chief Data Officer) со своими службами.

Система управления знаниями - это управленческие процедуры, призванные повысить эффективность сбора, хранения, распространения и использования ценной информации с точки зрения компании. Помимо преимуществ, цифровая трансформация несет и определенные риски [5].

Информационной безопасностью называют комплекс организационных, технических и технологических мер по защите информации от неавторизованного доступа, разрушения, модификации, раскрытия и задержек в доступе.

В архитектуру ИБ, безусловно, входят и организационные структуры, ответственные за соответственные зоны безопасности.

Архитектура рисков и информационной безопасности может быть составной частью ИТ инфраструктуры или выделенной в отдельные организационные структуры предприятия, но тесно взаимодействующие с подразделениями ИТ инфраструктуры.

Анализируя такой подход к рассмотрению архитектуры, мы можем предложить принципы формирования проектной команды разработчиков ИСМ и команды 
из состава руководителей и функциональных исполнителей предприятия.

Безусловно, команда разработчиков должна включать: специалиста в области управления качеством, бизнес-аналитика, финансового аналитика, архитектора решений, системного архитектора, ИТ-менеджера, менеджера информационных систем, менеджера систем информационной безопасности, менеджера рисков, менеджеров в области экологии и безопасности труда и др. Безусловно, из этого вытекает и кадровый состав службы качества предприятия и других функциональных подразделений. Кроме того, из этого следует, какой стандарт следует применять и на каком этапе создания ИСМ.

Особое место в проектировании ИСМ занимает процессная архитектура и сами бизнес-процессы. На основе процессного моделирования и декомпозиции бизнес-процессов можно получить всю необходимую информацию для проектирования цифрового предприятия и создания ИСМ [6].

Возглавляет данное направление Директор по информационной безопасности (Chief Information Security Officer) - руководитель подразделения ИТ-безопасности, (главный) директор по ИТ-безопасности. CISO может подчиняться как CIO, так и CSO.

Важное место в управлении ИТ услугами (сервисами) и информационной безопасностью влияют Управление рисками (ISO 3100). Выполнение предупреждающих действий, направленных на исключение потенциальных несоответствий, анализ любых несоответствий, которые возникают, и принятие мер по предотвращению их повторения, соответствующих последствиям несоответствия.

\section{Зак^ючение}

Проведённый анализ показывает, что, проектируя цифровое предприятие, предприятие эпохи «Индустрии 4.0», и создавая интегрированные организационно-функциональные системы менеджмента предприятия, необходимо учитывать повсеместное использование информационных систем и технологий, а также стандартов их применения и использования.

Информационные бизнес-процессы перешли из вспомогательных действий в основные, определяющие развитие всего бизнеса.

Поэтому при проектировании цифровых производств позволяет говорить об интегральном использовании опыта и методологии проектирования ИС, объектно-ориентированного проектирования, методологии проектирования архитектур предприятия, используя аппарат системного анализа и системно-процессного моделирования, инструментария менеджмента качества и системного подхода в создании инфраструктур цифрового предприятия.

\section{ЛИТЕРАТУРА}

1. В.Н. Азаров, Ю.Л. Леохин, «ИТ-инфраструктуры цифрового предприятия», Качество. Инновации. Образование. № 6, 2020.С.104-119.

2. Кирюшин С.Е., «Учебник 4СDТО Клуб ИТ-директоров 4СDТ0», Сам полиграфист, М., 2020.

3. «Analysis of Information Structure of the Corporate Network of Enterprise», 15-21, Saksonov Evgeny A., Leokhin Yury L., Azarov Vladimir N. 2018 IEEE International Conference "Quality Management, Transport and Information Security, Information Technologies" (IT\&QM\&IS) Year: 2018 | Conference Paper | Publisher: IEEE

4. The Approaches to the Design of Integrated Quality Management Systems for the Digital Enterprise. Vladimir N. Azarov, Valery P. Mayboroda, Yury L. Leokhin

5. Analysis of Information Structure of the Corporate Network of Enterprise. Vladimir N. Azarov, Evgeniy A. Saksonov, Yury L. Leokhin

6. Organization of Information Security in Industrial Internet of Things Systems. Evgeniy A. Saksonov; Yury L. Leokhin; Vladimir N. Azarov, PublicationYear: 2019, Page(s): 3-7D0I: 10.1109/ITQMIS.2019.

7. Azarov VN, Boytsov BV, Mayboroda VP / Challenges of the era of digital revolution. Transformation of Management and Quality Management / LAMBERT.Academic Publishing., ISBN: 978-613-9-46390-9.

8. Компетентность / ред. кол.: С.А. Калинцева и др.; гл. ред. Г.В. Панкина; учред. и изд. Академия стандартизации, метрологии и сертификации (АСМС).Москва: Академия стандартизации, метрологии и сертификации, 2017.— №9-10(150-151).— 88 c.: ил.— Режим доступа: URL: https://biblioclub.ru/ index.php?page=book\&id=482575 (дата обращения: 12.04 .2021 )

(c) Андрусенко Татьяна Анатольевна ( tati.and01@gmail.com ), Азаров Владимир Николаевич ( vazarov52@gmail.com ).

Журнал «Современная наука: актуальные проблемы теории и практики» 